\title{
DEWORMING ADJUCNT MIRONUTRIENT SUPPLEMENTATION IN INCREASING HAEMATOLOGIC INDICES AND ENHANCING NUTRITIONAL STATUS IN CHILDREN: RECENT OBSERVATION FROM BANGLADESH
}

\author{
K.S. Anwar ${ }^{1,2}$, A. Sayeda ${ }^{3}$, M.A.H. Mollah ${ }^{3}$, S. Nasreen ${ }^{3,4}$, A.M. Murtaza ${ }^{3}$, M.M. Zaman ${ }^{4,5}$ \\ ${ }^{I}$ Epidemiology Unit, Dept. of Microbiology, Institue of Public Health, ${ }^{2}$ Department of Microbiology, Hawtah \\ Sudair Hospital, ${ }^{3}$ Paediatrics, Dhaka Medical College Hospital (DMCH), ${ }^{4} B S M M U$ (Ex IPGM\&R) on \\ Deputation, Director General of Health Services, Dhaka, ${ }^{5}$ Paediatrics, Rangpur Medical College Hospital, \\ Rangpur, Bangladesh
}

Background: Anaemia and Iron-deficiency(ID) often acts synergistically, while intestinal parasitosis (IP) augments in developing nutritional anemia and-iron deficiency(NAID) rampant in resource constraint countries. Since no such study was reported from Bangladesh yet, we conducted this community-based intervention-study in a disadvantaged rural-area.

Methodology: Total 168, children(mean age $=6.86 \pm 2.33$ years) having intestinal parasitosis and anaemia, were subjected to fortnightly anthropometry and were randomized into 4 groups $(\mathrm{Gp})$ :Children from A1 \& A2 were dewormed and B1 \& B2 were not. Further, A1 and B1 were supplemented with micronutrient and A2 \& B2 were not. Haematological indices/micronutrient assay were done for all at baseline. Postintervened blood was re-tested to compare with baseline.

Findings: Prevalence of helminths(81.5\%) and protozoa(12\%)lowered down significantly after intervention in $\mathrm{A} 1$, than $\mathrm{A} 2, \mathrm{~B} 1$ and $\mathrm{B} 2(\mathrm{p}<0.001)$. Mean Hb increased in $\mathrm{A} 1$, than $\mathrm{A} 2(\mathrm{p}>0.00), \mathrm{B} 1(\mathrm{p}>0.005)$ and $\mathrm{B} 2$ (p>0.001). Mean S. ferittin increased in Gp.A1 than B1 $(\mathrm{p}<0.03)$, and A2 than B1 $(\mathrm{p}<0.03)$ and Mean Total Iron-Binding-capacity increased in $\mathrm{Gp} \mathrm{A} 1$ than $\mathrm{A} 2(\mathrm{p}<0.03)$ and $\mathrm{A} 2$ than $\mathrm{B} 2(\mathrm{p}>0.04)$.

While no post-intervened increment in mean height-z-score was observed except in A1 than B2 $(\mathrm{p}<0.04)$, Means weight-z-score was increased in A1 than A2(p<0.02), B1 than B2 $(p<0.001), A 2$ than $B 1(p<0.05)$ \& A2 than $\mathrm{B} 2(\mathrm{p}<0.05)$.

Conclusion: Micronutrient supplementation helps parasitic and/or anaemic children in increasing haematological indices and gaining weight if dewormed in prior. It is particularly essential in underdeveloped low-health care budgeted countries in adopting better policies/strategies towards better child survival, through a cost-effective sustainable prevention /control programs against NAID. 